\title{
Ambient temperature affects postnatal litter size reduction in golden hamsters
}

\author{
Sarah A. Ohrnberger ${ }^{1}$, Raquel Monclús ${ }^{2}$, Heiko G. Rödel ${ }^{3}$ and Teresa G. Valencak ${ }^{1 *}$
}

\begin{abstract}
Background: To better understand how different ambient temperatures during lactation affect survival of young, we studied patterns of losses of pups in golden hamsters (Mesocricetus auratus) at different ambient temperatures in the laboratory, mimicking temperature conditions in natural habitats. Golden hamsters produce large litters of more than 10 young but are also known to wean fewer pups at the end of lactation than they give birth to. We wanted to know whether temperature affects litter size reductions and whether the underlying causes of pup loss were related to maternal food (gross energy) intake and reproductive performance, such as litter growth. For that, we exposed lactating females to three different ambient temperatures and investigated associations with losses of offspring between birth and weaning.

Results: Overall, around one third of pups per litter disappeared, obviously consumed by the mother. Such litter size reductions were greatest at $30^{\circ} \mathrm{C}$, in particular during the intermediate postnatal period around peak lactation. Furthermore, litter size reductions were generally higher in larger litters. Maternal gross energy intake was highest at $5{ }^{\circ} \mathrm{C}$ suggesting that mothers were not limited by milk production and might have been able to raise a higher number of pups until weaning. This was further supported by the fact that the daily increases in litter mass as well as in the individual pup body masses, a proxy of mother's lactational performance, were lower at higher ambient temperatures.

Conclusions: We suggest that ambient temperatures around the thermoneutral zone and beyond are preventing golden hamster females from producing milk at sufficient rates. Around two thirds of the pups per litter disappeared at high temperature conditions, and their early growth rates were significantly lower than at lower ambient temperatures. It is possible that these losses are due to an intrinsic physiological limitation (imposed by heat dissipation) compromising maternal energy intake and milk production.
\end{abstract}

Keywords: Lactation, Litter size, Heat dissipation limitation, Juvenile growth, Pup mortality, Early development, Survival, Ambient temperature, Mesocricetus auratus

\section{Background}

Survival of pre-weaned pups is largely dependent on maternal behaviour, especially in mammalian taxa such as rodents with relatively undeveloped and altricial young that are fully dependent on their mothers for nutrition and thermoregulation early in life [1]. Under natural conditions as well as in laboratory rodents, single pups or entire litters are frequently lost shortly after birth [2]. It has been discussed that factors such as mother's age and experience, anthropogenically caused disturbance,

\footnotetext{
*Correspondence: Teresa.Valencak@vetmeduni.ac.at

${ }^{1}$ Institute of Physiology, Pathophysiology and Biophysics, Veterinary

University Vienna, Vienna, Austria

Full list of author information is available at the end of the article
}

parity and litter size at parturition play a role [3]. Although dead pups are often consumed by their mothers this does not necessarily imply that the female actively kills them [1]. While some studies exist that tested effects of prenatal heat exposure on later reproductive performance and pup growth after weaning $[4,5]$, there is only few research investigating effects of ambient temperature on the energy demands of lactating mothers and how this affects survival of pre-weaned young [6-9], particularly in small altricial mammals producing larger litters [10-12].

Effects of ambient temperatures on the survival of preweaned, altricial young can act on different levels. Direct influences of extreme temperatures can cause fatal 
overheating or cooling down of the young, frequently affecting survival of the whole litter $[6,10,13,14]$. However, temperature-dependent maternal effects can also play a role, through effects on milk production and behaviour of the mothers. It is commonly known that elevated body temperatures and heat stress in livestock animals cause distress and lead to an increased respiration rate, reduced activity and food intake and furthermore to negative effects on breeding performance by reducing fertility $[15,16]$. Conceivably, high ambient temperatures have adverse effects on milk production in species such as laboratory mice (Mus musculus) [17], common voles (Microtus arvalis) [18], Brandt's voles (Lasiopodomys brandtii) [19], Mongolian gerbils (Meriones unguiculatus) [20] but also in dairy cattle (Bos taurus) [21-24]. Undoubtedly, lactation is the phase when mammalian females show peak metabolic rates, thus having the highest energy consumption and expenditure [25-29]. Recently, various studies have been carried out to identify the "intrinsic" i.e., physiological limits by which females are constrained to further ingest food and transfer nutrients into milk, with consequences for the development of their offspring [17, 30-33]. It becomes clear from these studies that ambient conditions play a key role in this process $[6,18]$. We propose that in view of the wide applicability of the concept of heat limiting reproductive outcome, i.e., virtually to all breeding females facing quickly changing thermal conditions and increasingly warm temperatures, physiological mechanisms imposed on mothers may largely affect or even drive individual pup survival and growth. To investigate the associations between such mechanisms and constraints imposed to mothers and their potential impact on offspring survivability, one needs to monitor energy fluxes at different ambient conditions while observing growth and number of all young over the course of lactation and not only at birth and weaning. Under lab conditions, however, such data are often not obtained but rather, focus is given to the number of weaned, viable young, irrespective of the mortality of dependent pups.

When raising larger litters, lactating females undoubtedly reach peak sustained metabolic rates and expend energy at high rates [34-36]. Their body temperature increases [37], their organs work at peak rates, their gastrointestinal tract is widely extended to process and digest even more food [38-40]. Not surprisingly then, females reach a physiological limit where food intake stagnates and cannot be extended any further. Interestingly, the only manipulation that sufficiently enables females to maximise food intake is reducing ambient temperature below the thermoneutral zone i.e., the temperature area where mammals do not need to spend energy on maintenance of their own constant body temperature [30, 41, 42]. At lower ambient temperatures, the females seemingly can raise their energy intake and transform ingested food better into milk as was shown in laboratory mice [41], in striped hamsters (Cricetulus barabensis) $[43]$ and in voles $[18,19]$. Yet, very often, lactating laboratory mice are exposed to warmer rather than chilled conditions, and it has been argued that laboratory mammals should be housed at $30{ }^{\circ} \mathrm{C}$ to best mimic the thermal conditions experienced by humans [44]. However, comparing the thermoregulatory curves of humans and mice suggests that the optimal temperature for single housed mice is in the range of 23 to $25^{\circ} \mathrm{C}$, and around 20 to $22{ }^{\circ} \mathrm{C}$ for group housed mice [45].

The general aim of this study was therefore to investigate the link between ambient temperature and pre-weaning pup survival, as reflected by litter size reductions. We conducted this study in golden hamsters (Mesocricetus auratus), which are frequently used as pets and as laboratory animals. Golden hamsters are native of the Aleppinian plateau in Syria where they are exposed to huge fluctuations in ambient temperature of $-4{ }^{\circ} \mathrm{C}$ to $35{ }^{\circ} \mathrm{C}$, not only between summer and winter, but also diurnally during the summer months [46]. Most impressively, they have the shortest gestation period reported in eutherian mammals, of ca. 16-18 days [47]. They give birth to litters of variable sizes of up to 16 young and are therefore expected to produce large quantities of milk until pups reach a selfsustaining state. Apparently, litter sizes do not differ between laboratory strains and wild-derived golden hamsters [48]. Under laboratory conditions, female golden hamsters have been reported to actively reduce litter size [3]. These events have often been described as behavioural pathology and mostly attributed to anthropogenically caused distress, disruption of maternal behaviour $[49,50]$ or as a reaction to very large litter sizes [3].

We bred female golden hamsters at their thermoneutral $\left(30{ }^{\circ} \mathrm{C}\right)$ and below their thermoneutral zone (22 and $5{ }^{\circ} \mathrm{C}$ ). We followed the litters from birth to weaning and recorded the occurrence of litter size losses at different ambient temperature conditions. We hypothesised that females kept at lower temperatures would be better able to get rid of excess metabolic heat produced during lactation, and increase their food (gross energy) intake. Therefore, we $(i)$ expected to find a positive effect of low ambient temperature conditions on the increase in total litter mass as well as on individual pup growth as a proxy of mother's lactational performance. However, low temperatures might also give rise to higher associated thermoregulatory costs for mothers and in particular for the offspring, as may be apparent in lower offspring growth $[6,51]$. Moreover, we predicted that at lower ambient temperatures (ii) females would be able to increase their food intake to cover the increasing energetic demands of lactation. If females can compensate for the higher energetic demands of lactation at lower 
temperatures (iii) they might be better able to raise larger litters, and thus, litter size reductions might be minimised.

\section{Results}

\section{Litter size reduction}

On average, around $37.7 \%$ of pups per litter disappeared during the time of study, and such litter size reductions varied between 0 and $100 \%$.

The reduction in the number of pups per litter differed significantly among the mothers kept at the three ambient temperatures (GLMM for Poisson distributed data: $\left.X_{1}^{2}=33.10, P<0.001\right)$. Litter size reductions were significantly higher when mothers and pups were kept at $30{ }^{\circ} \mathrm{C}$ than at $5{ }^{\circ} \mathrm{C}$ or $22{ }^{\circ} \mathrm{C}$ (post hoc comparisons in Fig. 1a). Furthermore, the reduction in the number of pups was positively associated with litter size, i.e., there was a higher loss of pups in larger litters $\left(\chi_{1}^{2}=13.94\right.$, $\beta=0.126 \pm 0.031$ SE, $P<0.001$; Fig. $1 b)$. There was no significant interaction between litter size and ambient temperature on the reduction in the number of pups $\left(\chi_{1}^{2}=1.90, P=0.39\right)$, indicating that the effects of these two predictors were independent from each other.

In addition, a more fine-scaled analysis revealed that the significantly higher litter size reduction in the $30{ }^{\circ} \mathrm{C}$ group compared to the $5{ }^{\circ} \mathrm{C}\left(\chi_{1}^{2}=72.48, P<0.001\right)$ and $22{ }^{\circ} \mathrm{C}\left(\chi_{1}^{2}=49.80, P<0.001\right)$ particularly occurred during the middle part of the lactation period (postpartum days 7-12). Litter size reductions during the early period (postpartum days 1-6) and later period (days 13-19) did not significantly differ between the three ambient temperature conditions (all $P>0.10$ ).
There were no significant effects of mother's body mass and age in any of these analyses (all $P>0.10$ ).

\section{Maternal gross energy intake}

We quantified mothers' gross energy intake (GEI) until postpartum day 10, based on the intake of pellets and mothers' additional consumption of dead pups. We chose this time interval, as golden hamster pups usually start feeding on solid food at around postnatal day 11, thus making it difficult to quantify the amount of food ingested by the mother within a cage as soon as pups reach this age. Mean values of GEI, averaged over this time span differed significantly among the three ambient temperature conditions (LMM; $F_{2,345}=159.94, \quad P<$ 0.001). Pairwise comparisons (all $P<0.001$ ) revealed that the GEI including the consumed pups was significantly higher at $5{ }^{\circ} \mathrm{C}(651.4 \mathrm{~kJ} /$ day $\pm 67.4 \mathrm{SD})$, intermediate at $22{ }^{\circ} \mathrm{C}(503.6 \mathrm{~kJ} /$ day $\pm 65.1 \mathrm{SD})$ and lower at $30{ }^{\circ} \mathrm{C}$ $(290.1 \mathrm{~kJ} /$ day $\pm 64.8 \mathrm{SD})$.

Mothers' GEI showed differential dynamics over the first 10 days of lactation at the three different ambient temperature conditions (day of lactation $\times$ ambient temperature; $F_{2,479}=67.61, P<0.001$ ). The energy intake increased significantly during all temperature conditions $\left(5{ }^{\circ} \mathrm{C}: \beta=386.73 \pm 17.20, P<0.001\right.$, Fig. 2 a; $22{ }^{\circ} \mathrm{C}: \beta=$ $356.53 \pm 17.18$ SE, $P<0.001$, Fig. 2 b; $30{ }^{\circ} \mathrm{C}: \beta=62.44 \pm$ 20.97 SE, $P=0.004$, Fig. 2c). However, post hoc comparisons revealed that the slopes of these increases were significantly steeper at $5{ }^{\circ} \mathrm{C}$ and $22{ }^{\circ} \mathrm{C}$ than at $30{ }^{\circ} \mathrm{C}$ (all $P<0.001$ ), whilst the slopes at $5{ }^{\circ} \mathrm{C}$ and $22{ }^{\circ} \mathrm{C}$ did not significantly differ from each other $(P>0.05)$. In addition, GEI was significantly and positively associated with the current number of pups alive during
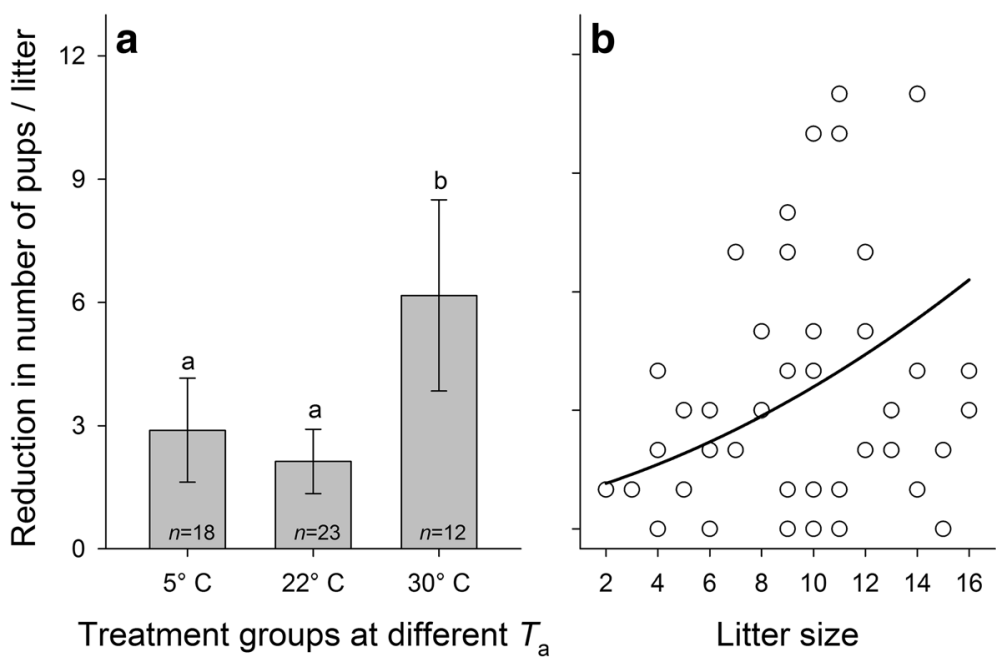

Fig. 1 Effects of (a) ambient temperature $T_{a}$ and (b) litter size on litter size reduction. Reduction in the number of pups per litter in (a) are given as means $\pm 95 \%$ confidence intervals., Significant pairwise comparisons between ambient temperature conditions (Bonferroni corrected post-hoc comparisons by GLMM for Poisson distributed data) are indicated by different letters. $\mathbf{b}$ Litter size was quantified on postnatal day 1 . Regression line is based on parameter estimates of a multifactorial GLMM for Poisson distributed data; see text for details on statistics 


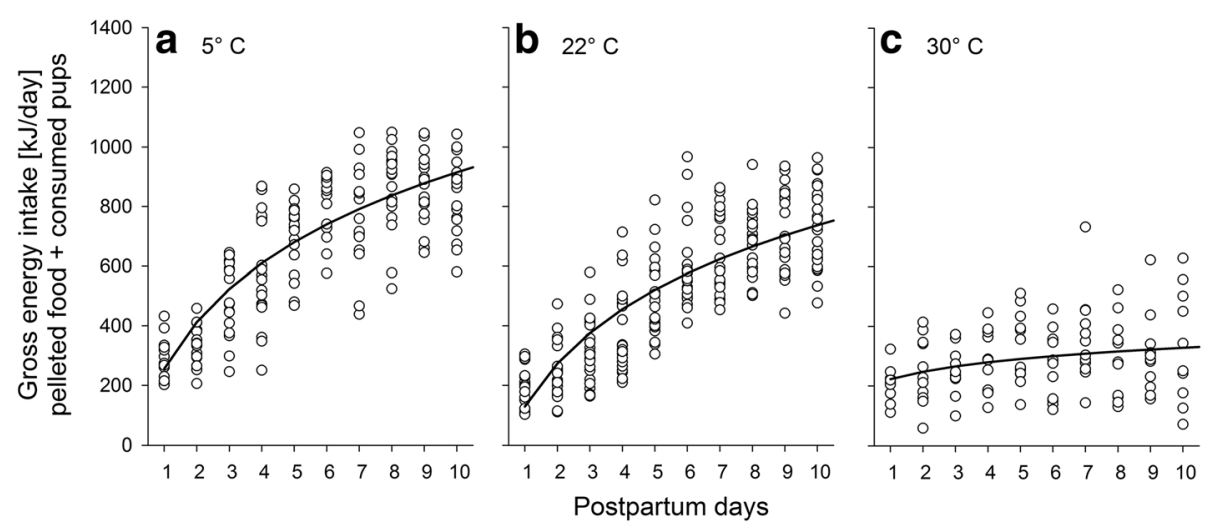

Fig. 2 Mothers' gross energy intake (GEI) during early lactation under different ambient temperature conditions $\left(\mathbf{a}: 5^{\circ} \mathrm{C} ; \mathbf{b}: 22^{\circ} \mathrm{C} ; \mathbf{c}: 30^{\circ} \mathrm{C}\right)$. The daily GEl considering the amount of pelleted food and the pups consumed by the mother are given for the first 10 days postpartum, before the young started to feed on pelleted food. Regression lines are based on the back-transformed parameter estimates calculated by LMM; see text for details on statistics

the different postnatal days $\left(F_{1,65}=5.69, \beta=6.18 \pm\right.$ 2.59 SE, $P=0.020)$.

Mother's body mass and age, or litter size were not significantly associated with GEI in any of these analyses $(P>0.10)$.

\section{Increases in individual pup mass and in total litter mass}

The daily increase in the individual (averaged) pup body masses, measured between postnatal days 3 and 5, differed significantly between the different ambient temperature conditions (LMM: $F_{2,27}=14.56 ; P<0.001$ ), with significantly higher increases at $5{ }^{\circ} \mathrm{C}$ in comparison to the increases observed under $22{ }^{\circ} \mathrm{C}$ and $30{ }^{\circ} \mathrm{C}$ (post-hoc comparisons in Fig. 3a). Furthermore, the increase in individual (averaged) pup body masses decreased significantly with increasing litter size $F_{1,31}=7.87$; $\beta=-0.018 \pm 0.006$ SE, $P=0.009$; Fig. 3b).

Similar results were obtained when total litter masses were analysed. These also significantly differed among the different ambient temperature conditions $\left(F_{2,33}=\right.$ 4.73; $P=0.016$ ). Post hoc comparisons revealed significantly higher litter masses at $5{ }^{\circ} \mathrm{C}$ in comparison to the litter masses found at $30{ }^{\circ} \mathrm{C}\left(F_{2,33}=9.50 ; P=0.008\right)$. There were, however, no significant differences between the litter masses at $5{ }^{\circ} \mathrm{C}$ and $22{ }^{\circ} \mathrm{C}$ and between the litter masses at $22{ }^{\circ} \mathrm{C}$ and $30{ }^{\circ} \mathrm{C}$ (both $P>0.05$ ). Also here, there was a
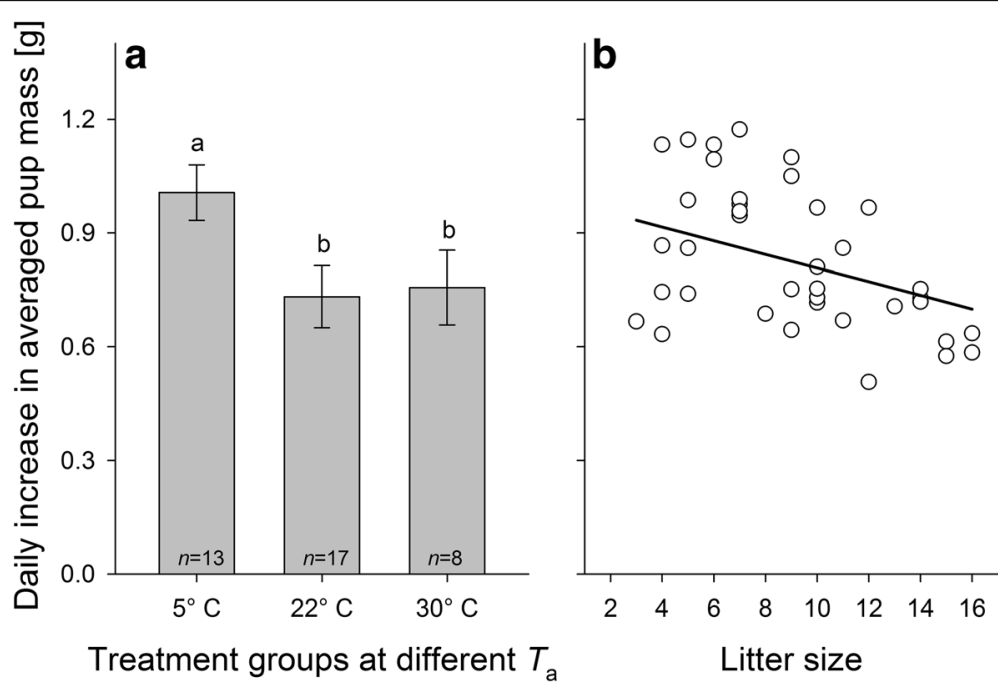

Fig. 3 Effects of (a) ambient temperature $T_{a}$ and (b) litter size on the daily increase in average pup body mass. Increases in the averaged individual pup body mass in (a) are given as means $\pm 95 \%$ confidence intervals. Significant pairwise comparisons between ambient temperature conditions (Bonferroni corrected post-hoc comparisons by LMM) are indicated by different letters. b Litter size was quantified on postnatal day 1. Regression line is based on parameter estimates of a multifactorial LMM; see text for details on statistics. Averaged daily changes in litter mass and in pup body mass were measured between postnatal days 3 and 5; only cases where no pup loss occurred during this time were considered 
significant, although positive association between litter mass and litter size $\left(F_{1,34}=58.74 ; \beta=0.489 \pm 0.064 \mathrm{SE}\right.$, $P<0.001)$.

There were no significant effects of mother's body mass and age on the daily increase in litter mass or on the daily increase in the individual (averaged) pup body mass (all $P>0.10$ ).

\section{Discussion}

We observed that litter size reduction in golden hamsters from birth to weaning was ambient-temperature dependent, being highest at $30{ }^{\circ} \mathrm{C}$. Furthermore, mothers increased their GEI with decreasing ambient temperature. Moreover, daily increase in litter mass and in pup body mass were higher, the lower the ambient temperature was.

\section{Litter size reduction}

The averaged litter size reduction in our study was $37.7 \%$ pups per litter, although with a high variability ranging from $0-100 \%$. Multifactorial modelling revealed that this reduction was partly dependent on initial litter size, with higher reductions occurring in larger litters. Such a higher probability of litter size reduction in larger litters is already well known [10, 52, 53]. This could be mainly attributed to the fact that mammalian mothers of polytocous species typically cannot fully compensate for the increased need of milk production when giving birth to larger litters, thus leading to a lower share of milk available to each individual offspring $[52,54,55]$. Such a negative correlation between litter size and individual pup growth was also confirmed by the results of our study. Furthermore, and as it is has also been suggested for other species of mammals and birds, the probability that mothers adaptively and actively reduce the number of offspring by partial infanticide is increased when litter size is high and offspring's needs exceed mothers' available resources $[52,56]$.

In addition to the observed litter size effects, litter size reductions were highest at an ambient temperature of $30{ }^{\circ} \mathrm{C}$, as exemplified by an average loss of $63.5 \%$ of the pups per litter under such conditions. In contrast to our findings, it has been reported for common voles that pup survival was increased at $30^{\circ} \mathrm{C}$, despite experiencing lower growth rates, most likely because pups benefited from the lower maintenance costs at higher ambient temperatures [18]. These contradictory findings in different species of rodents might indicate that at $30{ }^{\circ} \mathrm{C}$, the observation of maternal investment (i.e., negative effects of heat on milk production) and the consequences on the offspring (less energy expenditure for thermoregulation) might be species-specific.

One potential explanation for the observed litter size reduction in the group of the $30{ }^{\circ} \mathrm{C}$ mothers could be that heat load or even heat stress might have caused overheating leading to abnormal maternal behaviour or less viability of the offspring, thus resulting in a lowered litter size [13]. Moreover, at $30{ }^{\circ} \mathrm{C}$, reductions were highest around day 7-10 of lactation, that is, at a time point close to peak lactation, when young still rely solely on milk but have a substantially higher demand than at the beginning of lactation [57]. We hypothesize that when peak lactation gets closer and energy demands become even higher, females rather terminate lactation (as manifest in the reduction of pups), than risking hyperthermia.

Litter size reductions might have arisen from several scenarios, which we could not disentangle in this study: Mothers might have actively reduced their litter by killing and consuming their pups [58]. And/or pups might have died and mothers (or even siblings, at least at an older age) might have consumed them. Independently of the imminent causes of death of the pups in the litter, we propose that the reduction in litter size may originate from physiologically imposed energetic constraints that prevent mothers from producing milk at required rates and that reductions in the number of pups were related to metabolism and growth of young cf [57].

\section{Differences in maternal gross energy intake}

Indeed, ambient temperature had a significant effect on mother's gross energy intake (GEI), which increased over the course of the early lactation period particularly at lower ambient temperatures. In contrast, mother's GEI remained rather constant, showing a significantly lower increase when animals were housed at $30{ }^{\circ} \mathrm{C}$. One possible explanation might be that mothers exposed to such ambient temperature conditions had notably lower energetic demands than mothers under other temperature treatments.

Maternal GEI in our study also depended on the current litter size through the course of lactation; i.e., females raising larger litters had higher GEIs, and adjusted their GEIs to their changing needs, as it is typically found in small altricial mammals with an income breeding strategy [29, 33, 57]. Further evidence for the income strategy in golden hamsters comes from the fact that maternal body mass, as a proxy of maternal body condition and fat reserves, was not found to be significantly associated to mothers' GEI in our study. However, such effects have been reported in studies on other species $[29,59]$, and we cannot exclude that maternal reserves might play a role in this species when food resources are limited.

\section{Pup growth and increases in total litter mass}

In those cases where no litter reduction occurred, pup growth measured during the early postnatal period (days 3-5) was highest at $5{ }^{\circ} \mathrm{C}$. The same result was also apparent with respect to the increase in total litter mass, which could be used as a proxy of mothers' lactational performance. Pups raised at lower ambient temperatures 
of $5{ }^{\circ} \mathrm{C}$, just as in our experiment, might have higher energy and maintenance costs for processes such as thermoregulation and growth, which could result in lower growth capacity in those pups leading to lower weaning masses [60]. However, in our study lower temperatures boosted pup growth rates. This is concurrent with other reports showing that mammalian females produce more milk when they are exposed to lower temperatures [18-20, 38, 41, 61, 62]. The rationale behind this effect is that females might face an endogenous physiological limitation imposed by their capacity to dissipate the excess heat produced by the metabolism when organ systems work at peak rates, e.g., during lactation, the undoubtedly most demanding phase in the life of a female mammal $[25,30,63]$. When females are released from this limit, their capacity to metabolise nutrients from food increases [31]. Specifically, these findings suggest that mothers were able to ingest more energy, as in our study, and as a consequence, produced more milk when being released from excessive metabolic heat, for instance through exposure to moderate cold [28, 30, 38, 64]. Interestingly, as this effect was found in our study between postnatal days 3 and 5, it was widely independent of reductions in litter sizes that mostly occurred later on, between postnatal days 7 to 12 .

\section{Conclusions}

Taken together, our results suggest that lactating golden hamsters - when housed at ambient temperatures within or above their thermoneutral zone - are limited in their energy allocation to milk production. The ambienttemperature-dependent litter size reduction, which was highest at $30{ }^{\circ} \mathrm{C}$, was probably due to an intrinsic physiological limitation (imposed by heat dissipation), which might have compromised maternal energy intake and milk production. If we accept heat as eminent limiting factor during lactation, females may choose from two options. Firstly, they may risk overheating but still try to maximise GEI with all concomitant consequences. Alternatively, they may limit maternal investment by active litter size reduction (and thus will gain energy by consuming these pups) but rather tolerate the heat. Additional tactics potentially playing a role under natural conditions, such as mother's active exposure to colder environmental conditions cf. [46], should be explored in further experiments. In conclusion, our study highlights the necessity to carefully consider this result when setting temperature conditions in controlled housing of laboratory rodents as well as of pet animals in private homes.

\section{Methods}

\section{Animals and housing}

Laboratory golden hamsters were obtained from Charles River Laboratories (Sulzfeld, Germany). Using these animals, we started a breeding stock of golden hamsters in our laboratory. From this F1-colony we used a total of 32 females and 10 males in our study. The animals were between 70 and 330 days old, were regularly paired and were allowed to raise litters consecutively (1-4 litters per individual female). We housed them individually in polycarbonate cages (Eurostandard Type IV, $595 \times 380 \times$ $200 \mathrm{~mm}$, Techniplast, Germany). Cages equipped with autoclaved wood shavings (Abedd, Ssniff, Germany) were cleaned once a week, unless it coincided with the day of parturition, when females were not disturbed, and special attention was given to late pregnant and early lactating females. All animals were kept on a L:D 16:8 photoperiod. Before and during the pairing all animals were kept at $22{ }^{\circ} \mathrm{C}$. To ensure that all females became pregnant they were paired with males for 4 days, after which the males were removed. Pregnancy was observed by an increase in body mass over 7 days following the mating. On day 7 after mating all pregnant hamsters were randomly assigned to one of three treatment groups with different temperature settings of 5, 22 and $30{ }^{\circ} \mathrm{C}$, and remained under these different temperature regimes until the end of lactation on postnatal day 19. On postnatal day 19 litters were separated from their mothers and all females returned to $22{ }^{\circ} \mathrm{C}$. To expose hamster females to $5{ }^{\circ} \mathrm{C}$, their cages were put in a refrigerated counter (Zoin, Italy), commonly used as counter for cold products offered in supermarkets. That unit warrants constant temperature regulation throughout $24 \mathrm{~h}$ a day, has a limited noise production to which the animals easily habituate and finally is open on one side to allow air to flow freely. To generate the $30{ }^{\circ} \mathrm{C}$ environment, the animal room was heated up to $30{ }^{\circ} \mathrm{C}$. To monitor stability of ambient temperatures at both $5{ }^{\circ} \mathrm{C}$ and $30{ }^{\circ} \mathrm{C}$, we used temperature loggers (DS1921G-F5, Thermochron iButton, Maxim Integrated, USA) with an accuracy of $\pm 1{ }^{\circ} \mathrm{C}$ that were placed in each female's cage. With the aid of this method, we took measurements every $3 \mathrm{~h}$ throughout lactation revealing constant temperatures at all ambient temperature conditions.

\section{Data collection}

All measurements (GEIs, body masses of mothers and pups) were taken daily between 08:00 $\mathrm{h}$ am and 11:00 $\mathrm{h} \mathrm{am}$. The day when pups were found was considered as the day of parturition, referred to as day 0 of lactation. To minimize disturbances, all measurements were suspended on the day of parturition. Females had ad libitum access to food and water throughout the experiment at all different ambient temperature conditions. Daily food intake (in g) was continuously monitored except during the mating period. To this end, the animals were provisioned with a fixed amount of pelleted food during lactation. Fresh supply was provided and weighed 
in the morning if necessary. The remaining pellets from the previous day were weighed and the difference (consumption) was noted. All animals received the same diet during the experiment (commercial hamster diet, Ssniff, Germany). The rooms where the experiments took place were accessible only to 4 people, who were following very strict hygiene protocols.

\section{Reproduction}

Females gave birth approximately 17 to 21 days after introduction of the males and the average litter size observed was 9.3 pups ( $\pm 3.6 \mathrm{SD}$; min: 2 pups, max: 16 pups). Interestingly, females gave birth to different litter sizes in the three temperature treatment groups (GLMM for Poisson distributed data: $\left(\chi_{1}^{2}=15.94, P<0.001\right)$. At $22{ }^{\circ} \mathrm{C}$, mothers gave birth to significantly larger litters of on average 11.3 pups $( \pm 3.5 \mathrm{SD})$. However, mothers had litters with on average 7.8 pups $( \pm 2.8 \mathrm{SD})$ at $5{ }^{\circ} \mathrm{C}$ and 7.8 pups $( \pm 3.3 \mathrm{SD})$ at $30^{\circ} \mathrm{C}$, which did not differ statistically (pairwise post-hoc comparisons by GLMM).

\section{Litter size reduction}

Litter size reduction was monitored daily by comparing the number of pups per litter on each given day with the counts on the previous day. It is very unlikely that litter reduction was due to human disturbance, as the animals were used to daily handling and care by us. The fact that we also observed very large litters with few or no reductions further supports this argumentation.

\section{Mother's body mass and gross energy intake}

From day 1 of lactation onwards, we continuously measured mother's body mass, pup number and total litter mass on a daily basis. Measurements of mother's weights were then averaged within each reproductive event from postpartum day 1 to 19 , revealing an average maternal body mass of $144.2 \mathrm{~g} \pm 13.6 \mathrm{SD}$ (min: $117.1 \mathrm{~g}$; max: $187.7 \mathrm{~g})$.

Daily dry food consumption was measured as the difference between the amount (in g) of pelleted food provided to the mother and the remaining amount found in the cage $24 \mathrm{~h}$ later. To this end, the cage floor and the bedding (wood shavings) were checked daily for pieces of uneaten food, which were weighed and carefully put back into the cage to not disturb the females' food hoarding behaviour. In preliminary studies, we observed that these food items can make up a large proportion of the consumed food both by females and pups (late in lactation). Mother's gross energy intake (GEI) was then calculated by multiplying the daily intake of pelleted hamster food in g/day by its energy content of $16.5 \mathrm{~kJ} / \mathrm{g}$ (data provided by Ssniff, Germany). Furthermore, we added the energy content of the pups presumably consumed by the mother. For calculation, we assumed an energy content of golden hamster pups of $2.41 \mathrm{kcal} / \mathrm{g}$, as it had been suggested for juvenile laboratory mice of the same age class [31]. In absence of the possibility to measure the energy content of dead hamster pups and in view of the many similarities in juvenile development in rodents in general, we considered this approach both reasonable and justifiable.

Note that between around postnatal days 11 to 13, juvenile golden hamsters usually start picking up solid food themselves (pers. obs. SAO \& TGV). Thus, maternal GEI was compared between the different treatment groups only during the first 10 days postpartum.

\section{Increase in litter mass and average individual pup growth}

As outlined above, we measured total litter mass and the number of pups present daily to the nearest gram. To weigh the litters and to count the pups without largely disrupting maternal behaviour, we carefully took the female out of her cage, first to weigh her (see above) and then gently put her back right after by providing some extra bedding material (unbleached chemical pulp, Pehazell ${ }^{\circ}$ Hartmann, Germany). This procedure makes females to rapidly pick up and temporarily store the new bedding material inside their cheek pouches. We made use of this short time interval to quickly but gently take out the pups, weigh and count them and carefully put them back into the nest by covering it with the existing bedding. To assess the daily increase in litter mass and in the average pup mass, we compared the litter masses from one day to the next by dividing them by the number of pups in the nest on that particular day.

\section{Statistical data analysis and sample sizes}

All statistical analyses were performed using $\mathrm{R}$, version 3.2.0 [65]. We applied multifactorial linear mixed effects models, LMMs and generalized linear mixed effects models GLMMs for Poisson distributed data by using the $\mathrm{R}$ package lme4 [66]. Models always included mother identity as a random factor, as several litters (up to 4) were born from the same mothers. That is, the model structure accounted for repeated measurements of consecutive litters per female. Repeated reproductive events of individual females were assigned to different temperature conditions in the majority of cases (86\%) to reduce the chance that single mothers might bias the results by high numbers of repeated measurements within a particular treatment group. We also included parity (i.e., the continuous count of each mother's reproductive event) in our models as an additional random factor, as maternal performance might potentially differ between consecutive reproductive events [54, 67, 68]. Furthermore, maternal age and maternal mass were included as covariates, as these might potentially affect mothers' reproductive performance and offspring growth and 
mortality, as it has been shown in other small altrical mammals $[10,54]$. Both covariates were significantly correlated $\left(R^{2}=0.287, \beta=0.088 \pm 0.019 \mathrm{SE}, P<0.001\right)$, as mother's body mass increased with their age. Due to this collinearity, both covariates were never included simultaneously, but we always calculated separate models where we either tested for the effects of maternal mass or maternal age together with all other factor combinations considered (see below). Neither the effects of maternal body mass nor of maternal age were statistically significant in any of our analyses (all $P<0.10$ ). Thus, they were removed from the models before these were re-calculated.

Firstly, we tested for the effects of temperature conditions, litter size and maternal mass on the reduction in the number of pups from birth until weaning by GLMM for Poisson distributed data. For this analysis, the entire data set of $N_{\text {litters }}=53$ stemming from $N_{\text {mothers }}=32$ was used. In addition, we carried out a more specific analysis to identify during which part of the lactation period, purported differences in litter sizes reduction between the three ambient temperature conditions were more pronounced. To this end, we separately run the models for the early (postpartum days 1-6), middle (postpartum days 7-12) and late (postpartum days 13-19) lactation period.

Secondly, we analysed the effects of temperature conditions (factor with 3 levels), litter size and maternal mass (both covariates) on maternal GEI during the first 10 days of lactation with LMMs. For a more specific analysis on the dynamics of mothers' GEI over the period of lactation, litter identity was used as an additional random factor to account for the repeated measurements across the different postnatal days (see Fig. 2). The covariate "postnatal day" was log-transformed to account for the typical non-linear shape of GEI curves across the period of lactation [57]. This analysis was based on 512 daily measurements stemming from 53 litters from 32 different mothers. We statistically compared the slopes of the different increases over time by pairwise calculations ( 5 and $22{ }^{\circ} \mathrm{C} ; 5$ and $30{ }^{\circ} \mathrm{C} ; 22$ and $30{ }^{\circ} \mathrm{C}$ ) of the interactions between postnatal day and ambient temperature.

Finally, we analysed the effects of temperature conditions, litter size and maternal mass on the increase in litter mass and on the average daily pup growth from day 3 to 5 by LMMs. As all litters where mortality occurred during this period were excluded, the remaining sample size was consequently lower $\left(N_{\text {litters }}=38\right.$ stemming from $N_{\text {mothers }}=25$ ).

$P$-values of LMMs were obtained by type-II $F$-tests based on the Satterthwaite approximation, and $P$-values of GLMM were obtained by type-II Wald chi-square tests. Non-significant interaction terms were stepwise reduced from the models before these were re-calculated
[69]. We assured that the model residuals of LMM were well adjusted to a normal distribution by visually checking normal probability plots. Furthermore, we verified homogeneity of variances by plotting residuals versus fitted values for both, LMM and GLMM [70]. In addition, we added an individual-level random factor to all GLMMs (Poisson) to account for potential effects of overdispersion [71]. All multifactorial models were checked for multicollinearities by calculating variance inflation factors. These were lower than 2 in all cases, indicating no influential effects of multicollinearities [72]. For all significant covariate effects, the slope $(\beta)$ of the association including its standard error are given as a measure of effects size.

\section{Abbreviations \\ $\mathrm{T}_{\mathrm{a}}$ : Ambient temperature; GEl: Gross energy intake; GLMM: Generalized linear mixed effects models; LMM: Linear mixed effects models; $T_{a}$ : Ambient temperature \\ Acknowledgements \\ We are grateful to Violet Berger and Zsuzsanna Zsabo for their help and assistance with data collection as well as to the student helpers Rene Haider, Anna Mokry, Maria Thaler and Marilies Scheinost. We thank Felix Knauer for fruitful discussion and constructive criticism, and we thank our colleagues Hanno Gerritsmann and Christiana Winding for veterinary assistance. We would like to thank the thoughtful comments of two anonymous reviewers on earlier drafts, which greatly improved the manuscript.}

\section{Funding}

This study was financed through a single funded project from the Austrian Science Fund (FWF), grant number P 26246-B16 to TGV and is part of a larger study on heat dissipation limitation in hamsters. In addition, TGV received a grant for a research stay by the Université Paris 13, Sorbonne Paris Cité. RM was supported by a Marie Sklodowska-Curie action within the Horizon 2020 Initiative from the European Commission.

\section{Availability of data and material}

The dataset supporting the conclusions of this article is available at the Figshare repository: https://dx.doi.org/10.6084/m9.figshare.4244498.v1.

\section{Authors' contributions}

SAO and TGV designed the study. SAO and TGV conducted the experiment. RM, HGR and TGV conceptualised and completed the data analysis supported by SAO. SAO drafted the manuscript, which was completed to its current form by RM, HGR and TGV. All authors read and approved the final manuscript.

\section{Competing interests}

The authors declared that they have no competing interests.

Consent for publication

Not applicable.

\section{Ethics approval and consent to participate}

All experiments described here comply with the ARRIVE guidelines as well as with animal procedures at our university and in Austria. Prior to our study, the experiments were approved by the ethics committee of the University of Veterinary Medicine Vienna and the Austrian Ministry of Science (GZ 68.205/ 0035-WF/II3b/2014), and thus all necessary actions were undertaken according to $26 \mathrm{ff}$. of the Animal Experiments Act, (Tierversuchsgesetz 2012 - TVG 2012) in Austria.

\section{Author details}

${ }^{1}$ Institute of Physiology, Pathophysiology and Biophysics, Veterinary University Vienna, Vienna, Austria. ${ }^{2}$ Ecologie Systématique Evolution, University Paris-Sud, CNRS, AgroParisTech, Université Paris-Saclay, F-91400 
Orsay, France. ${ }^{3}$ Laboratoire d'Ethologie Expérimentale et Comparée E.A. 4443, Université Paris 13, Sorbonne Paris Cité, F-93430 Villetaneuse, France.

\section{Received: 21 August 2016 Accepted: 15 November 2016 Published online: 24 November 2016}

\section{References}

1. Weber EM, Olsson AS, Algers B. High mortality rates among newborn laboratory mice - is it natural and which are the causes? Acta Vet Scand. 2007:49:S8.

2. Morrison P, Dieterich R, Preston D. Longevity and mortality in 15 rodent species and subspecies maintained in laboratory colonies. Acta Theriol. 1977;22:317-35.

3. Day CS, Galef BG. Pup cannibalism: One aspect of maternal behavior in golden hamsters. J Comp Physiol Psychol. 1977;91:1179-89.

4. Hamid HY, Abu Bakar Zakaria MZ, Yong Meng G, Haron AW, Mohamed Mustapha N. Effects of elevated ambient temperature on reproductive outcomes and offspring growth depend on exposure time. Sci World J. 2012;2012:359134.

5. Russell AF, Clutton-Brock TH, Brotherton PNM, Sharpe LL, Mcilrath GM, Dalerum FD, et al. Factors affecting pup growth and survival in cooperatively breeding meerkats Suricata suricatta. J Anim Ecol. 2002;71:700-9.

6. Paul MJ, Tuthill C, Kauffman AS, Zucker I. Pelage insulation, litter size, and ambient temperature impact maternal energy intake and offspring development during lactation. Physiol Behav. 2010;100:128-34.

7. Marsteller FA, Lynch CB. Reproductive responses to variation in temperature and food supply by house mice II. Lactation. Biol Reprod. 1987;37:844-50.

8. Schneider JE, Wade GN. Effects of ambient temperature and body fat content on maternal litter reduction in Syrian hamsters. Physiol Behav. 1991;49:135-9.

9. Benderlioglu Z, Eish J, Weil ZM, Nelson RJ. Low temperatures during early development influence subsequent maternal and reproductive function in adult female mice. Physiol Behav. 2006:87:416-23.

10. Rödel HG, Starkloff A, Seltmann MW, Prager G, von Holst D. Causes and predictors of nest mortality in a European rabbit population. Mamm Biol. 2009;74:198-209.

11. Millar JS. Nest mortality in small mammals. EcoScience. 2007:14:286.

12. Bautista A, Drummond H, Martínez-Gómez M, Hudson R. Thermal benefit of sibling presence in the newborn rabbit. Dev Psychobiol. 2003:43:208-15.

13. Hearnshaw $\mathrm{H}$, Wodzicka-Tomaszewska M. Effect of high ambient temperature in early and late lactation on litter growth and survival in rats. Aust J Biol Sci. 1973:26:1171-8.

14. Hull D. Oxygen consumption and body temperature of new-born rabbits and kittens exposed to cold. J Physiol. 1965:177:192-202.

15. Kadzere CT, Murphy MR, Silanikove N, Maltz E. Heat stress in lactating dairy cows: a review. Livest Prod Sci. 2002;77:59-91.

16. Moore RB, Fuquay JW, Drapala WJ. Effects of late gestation heat stress on postpartum milk production and reproduction in dairy cattle. J Dairy Sci. 1992; 75:1877-82

17. Krol E. Limits to sustained energy intake VII. Milk energy output in laboratory mice at thermoneutrality. J Exp Biol. 2003;206:4267-81.

18. Simons MJP, Reimert I, van der Vinne V, Hambly C, Vaanholt LM, Speakman $J R$, et al. Ambient temperature shapes reproductive output during pregnancy and lactation in the common vole (Microtus arvalis): a test of the heat dissipation limit theory. J Exp Biol. 2011;214:38-49.

19. Wu S-H, Zhang L-N, Speakman JR, Wang D-H. Limits to sustained energy intake. XI. A test of the heat dissipation limitation hypothesis in lactating Brandt's voles (Lasiopodomys brandtii). J Exp Biol. 2009;212:3455-65.

20. Yang D-B, Li L, Wang L-P, Chi Q-S, Hambly C, Wang D-H, et al. Limits to sustained energy intake. XIX. A test of the heat dissipation limitation hypothesis in Mongolian gerbils (Meriones unguiculatus). J Exp Biol. 2013;216:3358-68

21. Yano M, Shimadzu $H$, Endo T. Modelling temperature effects on milk production: a study on Holstein cows at a Japanese farm. SpringerPlus. 2014;3:129.

22. Allen JD, Hall LW, Collier RJ, Smith JF. Effect of core body temperature, time of day, and climate conditions on behavioral patterns of lactating dairy cows experiencing mild to moderate heat stress. J Dairy Sci. 2015:98:118-27.

23. Moallem U, Altmark $G$, Lehrer $H$, Arieli A. Performance of high-yielding dairy cows supplemented with fat or concentrate under hot and humid climates. J Dairy Sci. 2010;93:3192-202
24. Srikandakumar A, Johnson EH. Effect of heat stress on milk production, rectal temperature, respiratory rate and blood chemistry in Holstein, Jersey and Australian Milking Zebu cows. Trop Anim Health Prod. 2004;36:685-92.

25. Millar JS. Adaptive features of mammalian reproduction. Evolution. 1977;31:370.

26. Glazier DS. Energetics of litter size in five species of Peromyscus with generalizations for other mammals. J Mammal. 1985;66:629-42.

27. Loudon ASI, Racey P. Reproductive energetics in mammals. Oxford: Oxford University Press; 1987.

28. Speakman JR, Król E. Limits to sustained energy intake. XIII. Recent progress and future perspectives. J Exp Biol. 2011;214:230-41.

29. Rödel HG, Valencak TG, Handrek A, Monclús R. Paying the energetic costs of reproduction: reliance on postpartum foraging and stored reserves. Behav Ecol. 2016;27:748-56.

30. Speakman JR, Król E. Maximal heat dissipation capacity and hyperthermia risk: Neglected key factors in the ecology of endotherms. J Anim Ecol. 2010;79:726-46.

31. Valencak TG, Wright $P$, Weir A, Mitchell SE, Vaanholt LM, Hambly C, et al. Limits to sustained energy intake. XXI. Effect of exposing the mother, but not her pups, to a cold environment during lactation in mice. J Exp Biol. 2013;216:4326-33.

32. Król E, Speakman JR. Limits to sustained energy intake. VI. Energetics of lactation in laboratory mice at thermoneutrality. J Exp Biol. 2003;206:4255-66.

33. Speakman JR, Król E. Limits to sustained energy intake IX: a review of hypotheses. J Comp Physiol B. 2005;175:375-94.

34. Zhang $X-Y$, Wang D-H. Thermogenesis, food intake and serum leptin in cold-exposed lactating Brandt's voles Lasiopodomys brandtii. J Exp Biol. 2007;210:512-21.

35. Wade GN, Schneider JE. Metabolic fuels and reproduction in female mammals. Neurosci Biobehav Rev. 1992;16:235-72.

36. Barber MC, Clegg RA, Travers MT, Vernon RG. Lipid metabolism in the lactating mammary gland. Biochim Biophys Acta. 1997:1347:101-26.

37. Gamo Y, Troup C, Mitchell SE, Hambly C, Vaanholt LM, Speakman JR. Limits to sustained energy intake. XX. Body temperatures and physical activity of female mice during lactation. J Exp Biol. 2013;216:3751-61.

38. Król E, Johnson MS, Speakman JR. Limits to sustained energy intake. VIII. Resting metabolic rate and organ morphology of laboratory mice lactating at thermoneutrality. J Exp Biol. 2003;206:4283-91.

39. Koteja P. Limits to the energy budget in a rodent, Peromyscus maniculatus: does gut capacity set the limit? Physiol Zool. 1996:69:994-1020.

40. Speakman JR, McQueenie J. Limits to sustained metabolic rate: The link between food intake, basal metabolic rate, and morphology in reproducing mice, Mus musculus. Physiol Zool. 1996;69:746-69.

41. Johnson MS, Speakman JR. Limits to sustained energy intake: V. Effect of coldexposure during lactation in Mus musculus. J Exp Biol. 2001;204:1967-77.

42. Speakman JR, Król E, Johnson MS. The functional significance of individual variation in basal metabolic rate. Physiol Biochem Zool. 2004:77:900-15.

43. Zhao Z-J. Energy budget during lactation in striped hamsters at different ambient temperatures. J Exp Biol. 2011:214:988-95.

44. National Research Council of the National Academies. Guide for the care and use of laboratory animals. 8th ed. Washington D.C.: National Academies Press; 2011

45. Speakman JR, Keijer J. Not so hot: Optimal housing temperatures for mice to mimic the thermal environment of humans. Mol Metab. 2013;2:5-9.

46. Gattermann R, Fritzsche P, Neumann K, Al-Hussein I, Kayser A, Abiad M, et al. Notes on the current distribution and the ecology of wild golden hamsters (Mesocricetus auratus). J Zool. 2001;254:359-65.

47. Bond CR. The golden hamster (Cricetus auratus): Care, breeding, and growth. Physiol Zool. 1945;18:52-9.

48. Fritzsche P, Neumann K, Nasdal K, Gattermann R. Differences in reproductive success between laboratory and wild-derived golden hamsters (Mesocricetus auratus) as a consequence of inbreeding. Behav Ecol Sociobiol. 2006;60:220-6.

49. Labov JB, Huck UW, Elwood RW, Brooks RJ. Current problems in the study of infanticidal behavior of rodents. Q Rev Biol. 1985;60:1-20

50. Hrdy SB. Infanticide among animals: a review, classification, and examination of the implications for the reproductive strategies of females. Ethol Sociobiol. 1979:1:13-40.

51. Biggers JD, Ashoub MR, McLaren A, Michie D. The growth and development of mice in three climatic environments. J Exp Biol. 1958:35:144-55. 
52. Mendi M. The effects of litter size variation on mother-offspring relationships and behavioural and physical development in several mammalian species (principally rodents). J Zool. 1988;215:15-34.

53. Andersen IL, Nævdal E, Bøe KE. Maternal investment, sibling competition, and offspring survival with increasing litter size and parity in pigs (Sus scrofa). Behav Ecol Sociobiol. 2011;65:1159-67.

54. Rödel HG, Prager G, Stefanski V, von Holst D, Hudson R. Separating maternal and litter-size effects on early postnatal growth in two species of altricial small mammals. Physiol Behav. 2008;93:826-34.

55. Mock DW, Parker GA. The evolution of sibling rivalry. Oxford: Oxford University Press; 1997.

56. Forbes LS. Avian brood reduction and parent-offspring "conflict". Am Nat. 1993;142:82-117.

57. Speakman JR. The physiological costs of reproduction in small mammals. Philos Trans R Soc Lond B Biol Sci. 2008:363:375-98.

58. Schneider JE, Wade GN. Effects of maternal diet, body weight and body composition on infanticide in Syrian hamsters. Physiol Behav. 1989:46:815-21.

59. Valencak TG, Tataruch F, Ruf T. Peak energy turnover in lactating European hares: The role of fat reserves. J Exp Biol. 2009;212:231-7.

60. Zhao Z-J, Song D-G, Su Z-C, Wei W-B, Liu X-B, Speakman JR. Limits to sustained energy intake. XVIII. Energy intake and reproductive output during lactation in Swiss mice raising small litters. J Exp Biol. 2013;216:2349-58.

61. Johnson MS, Thomson SC, Speakman JR. Limits to sustained energy intake: I. Lactation in the laboratory mouse Mus musculus. J Exp Biol. 2001;204:1925-35.

62. Zhao Z-J, Cao J. Effect of fur removal on the thermal conductance and energy budget in lactating Swiss mice. J Exp Biol. 2009;212:2541-9.

63. Gittleman JL, Thompson SD. Energy allocation in mammalian reproduction. Integr Comp Biol. 1988;28:863-75.

64. Król E, Murphy M, Speakman JR. Limits to sustained energy intake. X. Effects of fur removal on reproductive performance in laboratory mice. J Exp Biol. 2007;210:4233-43.

65. R Core Team. R: A language and environment for statistical computing. Vienna: R Foundation for Statistical Computing; 2015.

66. Bates $D$, Mächler $M$, Bolker B, Walker S. Fitting linear mixed-effects models using Ime4. J Stat Softw. 2015;67:1-48.

67. Innes DGL, Millar JS. Factors affecting litter size in Clethrionomys gapperi. Ann Zool Fennici. 1993;30:239-45.

68. Koivula M, Koskela E, Mappes T, Oksanen TA. Cost of reproduction in the wild: Manipulation of reproductive effort in the bank vole. Ecology. 2003;84:398-405.

69. Engqvist L. The mistreatment of covariate interaction terms in linear model analyses of behavioural and evolutionary ecology studies. Anim Behav. 2005:70:967-71.

70. Faraway JJ. Extending the linear model with R. Generalized linear, mixed effects and nonparametric regression models. Boca Raton: Chapman \& Hall/CRC; 2006

71. Browne WJ, Subramanian SV, Jones K, Goldstein H. Variance partitioning in multilevel logistic models that exhibit overdispersion. J Roy Stat Soc A. 2005:168:599-613.

72. Zuur AF, leno EN, Elphick CS. A protocol for data exploration to avoid common statistical problems. Methods Ecol Evol. 2010;1:3-14.

\section{Submit your next manuscript to BioMed Central and we will help you at every step:}

- We accept pre-submission inquiries

- Our selector tool helps you to find the most relevant journal

- We provide round the clock customer support

- Convenient online submission

- Thorough peer review

- Inclusion in PubMed and all major indexing services

- Maximum visibility for your research

Submit your manuscript at www.biomedcentral.com/submit

) Biomed Central 